
\title{
$\begin{array}{ll}\text { Research Square } & \text { Preprints are preliminary reports that have not undergone peer review. } \\ \text { They should not be considered conclusive, used to inform clinical practice, } \\ \text { or referenced by the media as validated information. }\end{array}$
}

\section{Using Topographic Attributes to Predict the Understorey Structure of a Wet Eucalypt Forest}

Bechu Kumar Vinwar Yadav ( $\square$ bechu.yadav@utas.edu.au )

University of Tasmania, School of Technology, Environments and Design, 4 Discipline of Geography and Spatial Sciences, Private Bag 70, Hobart, Tasmania 5 7001, Australia. https://orcid.org/0000-0002-10766099

\section{Arko Lucieer}

University of Tasmania, School of Technology, Environments and Design, Discipline of Geography and Spatial Sciences

\section{Gregory J. Jordan}

University of Tasmania, School of Natural Sciences, Biological Sciences

\section{Susan C. Baker}

University of Tasmania, School of Natural Sciences, Biological Sciences

\section{Research}

Keywords: Airborne LiDAR, Digital terrain model, Topographic attributes, 44 Geology, Understorey structure, Random forest, Variable importance

Posted Date: December 29th, 2020

DOl: https://doi.org/10.21203/rs.3.rs-135008/v1

License: (c) (i) This work is licensed under a Creative Commons Attribution 4.0 International License. Read Full License 


\section{Abstract}

Background: Forest understorey structure is an important component of forest ecosystems that affects forest-dwelling species, nutrient cycling, fire behaviour, biodiversity, and regeneration capacity. Mapping the structure of forest understorey vegetation with field surveys or high-resolution LiDAR data is costly. We tested whether landscape topography and underlying geology could predict the understorey structure of a $19 \mathrm{~km} 2$ area of wet eucalypt primary forest located at the Warra Long Term Ecological Research Supersite, Tasmania, Australia. In this study, we used random forest regressions based on twelve topographic attributes derived from digital terrain models (DTMs) at various resolutions and a geology variable to predict the densities of three understorey layers compared to density estimates from a high resolution (28.66 points/m2) LiDAR survey.

Results: We predicted the vegetation density of three canopy strata with a high degree of accuracy (validation root mean square error ranged from $8.97 \%$ to $13.69 \%$ ). 30 m resolution DTMs provided greater predictive accuracy than DTMs with higher spatial resolution. Variable importance depended on spatial resolutions and canopy strata layers, but among the predictor variables, geology generally produced the highest predictive importance followed by solar radiation. Topographic position index, aspect, and SAGA wetness index had moderate importance.

Conclusions: This study demonstrates that geological and topographic attributes can provide useful predictions of understorey vegetation structure in a primary forest. Given the good performance of $30 \mathrm{~m}$ resolution, the predictive power of the models could be tested on a larger geographical area using lower density LiDAR point clouds. This study should help in assessing fuel loads, carbon stores, biomass, and biological diversity, and could be useful for foresters and ecologists contributing to the planning of sustainable forest management and biodiversity conservation.

\section{Full Text}

This preprint is available for download as a PDF.

\section{Figures}




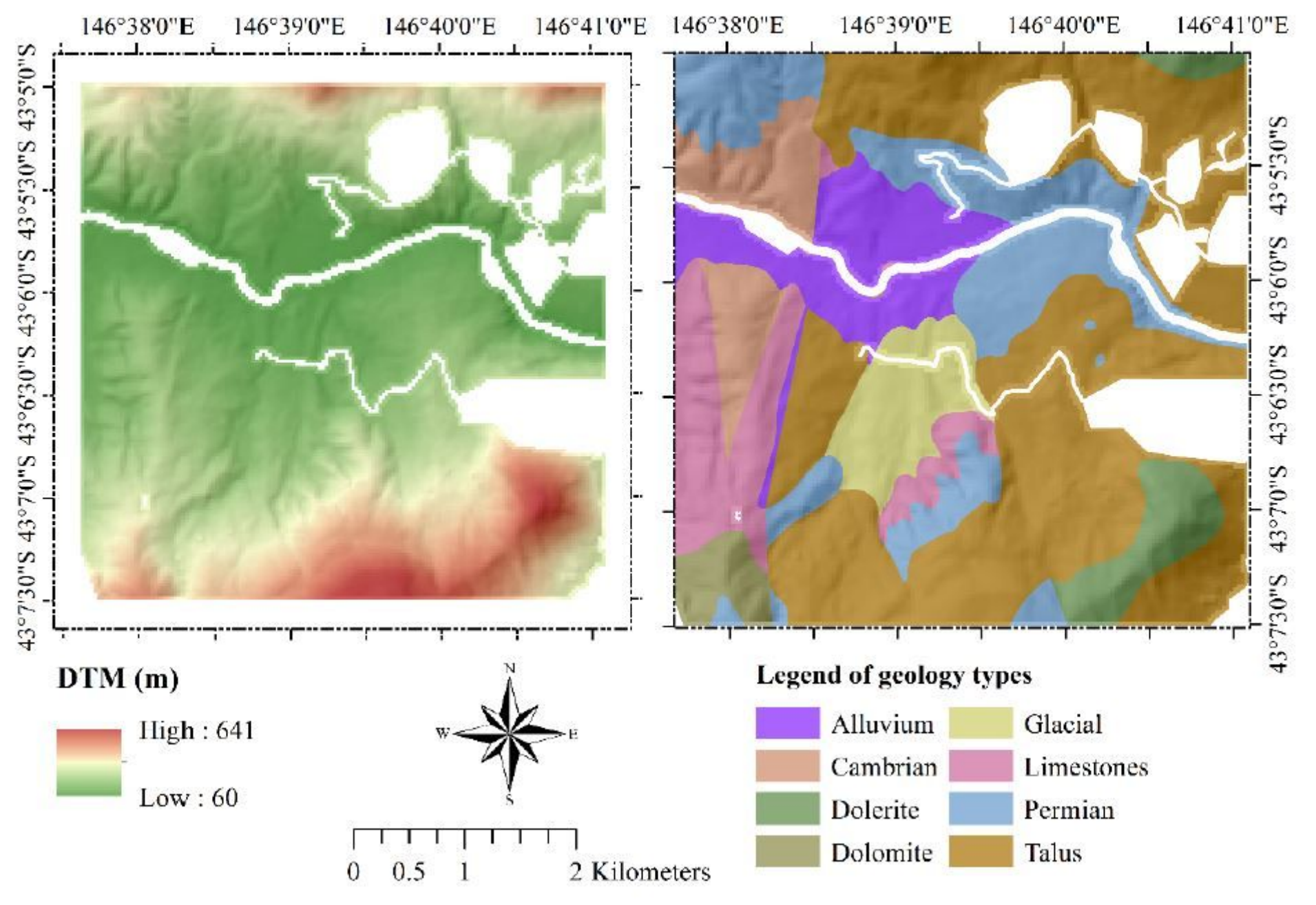

\section{Figure 1}

Maps of the study site showing the $30 \mathrm{~m}$ resolution digital terrain model (left) and geology (right). White areas removed from the analysis were roads, rivers, and previously harvested sites. Abbreviations of geology types are Quaternary alluvium (Alluvium), Cambrian siliceous sediments (Cambrian), Jurassic dolerite (Dolerite), Neoproterozoic dolomite (Dolomite), Glacial tills (Glacial), Permian sediments (Permian), and dolerite talus (Talus). 


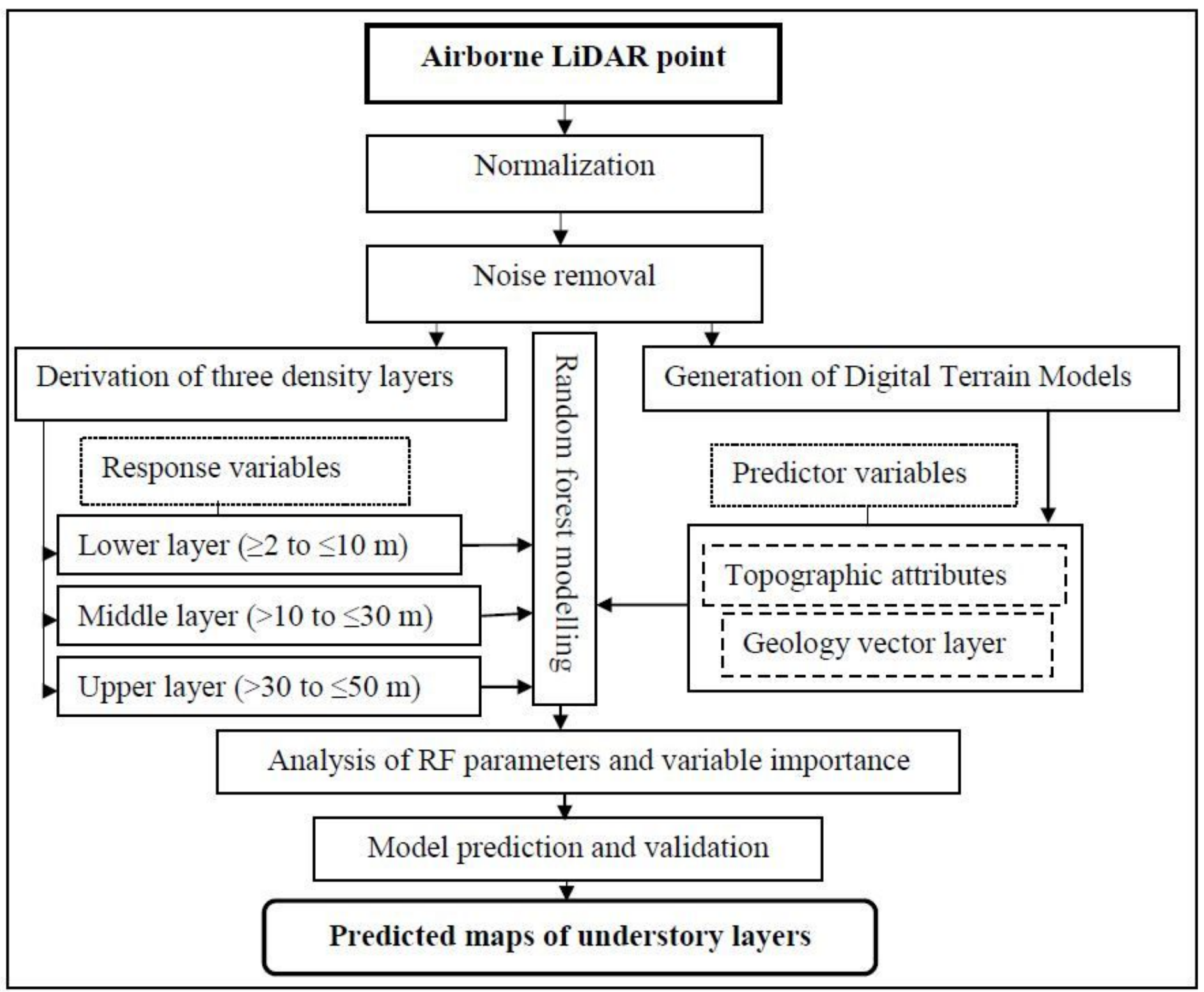

Figure 2

Workflow for testing the capacity for topography and geology to predict the density of vegetation in three canopy layers of a mature forest landscape. 

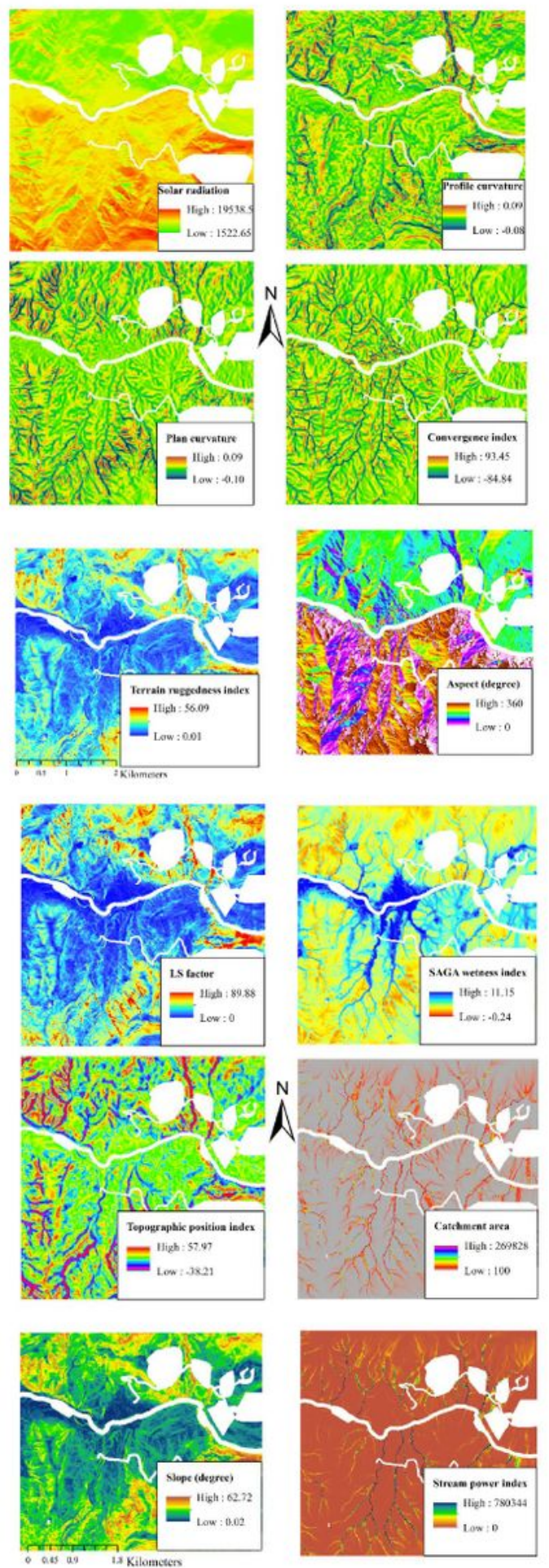

Figure 3

Maps of the twelve topographic attributes extracted from DTMs. 

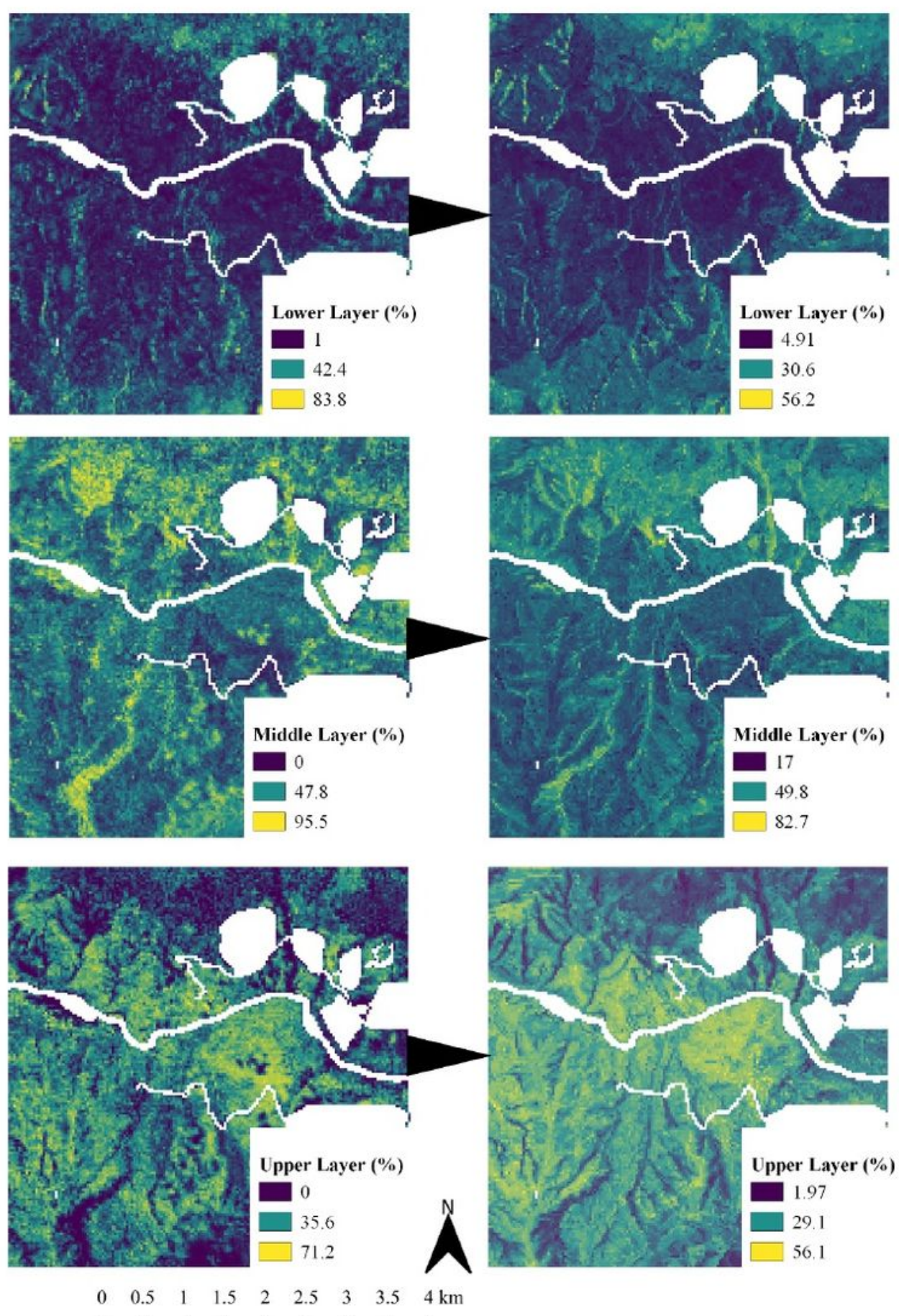

\section{Figure 4}

Maps comparing the density of forest understorey layers that were observed with high- resolution LiDAR data (left) with those predicted based on topography and geology (right) using $30 \mathrm{~m}$ resolution. Roads, rivers, and harvested areas appear as white. 


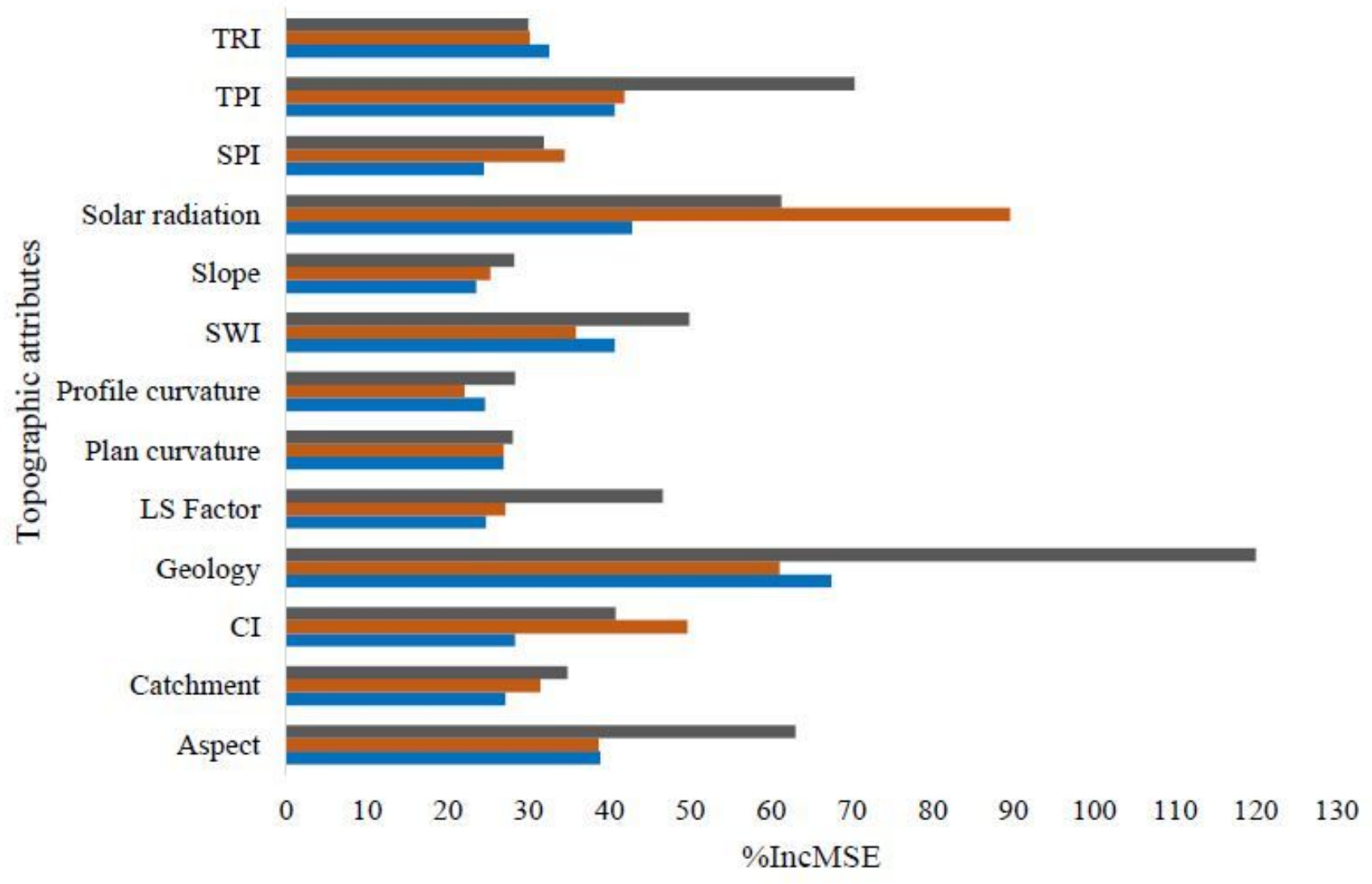

- Upper Layer $\quad$ Middle Layer $\quad$ Lower Layer

\section{Figure 5}

Variable importance scores (percentage increase in mean square error, \%IncMSE if the variable is eliminated from models) for topographic and geological attributes used in predicting the density of three vegetation canopy layers at $30 \mathrm{~m}$ spatial resolution. (Acronyms: Terrain Ruggedness Index (TRI), Topographic Position Index (TPI), Stream Power Index (SPI), SAGA Wetness Index (SWI), and Convergence index $(\mathrm{Cl}))$. 


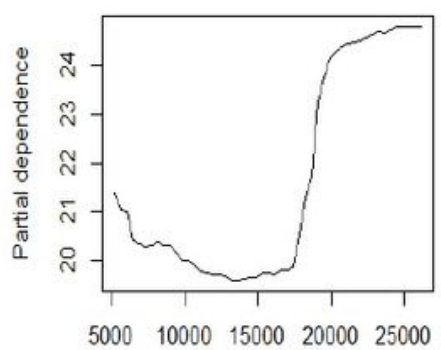

Solaradiation_Lower

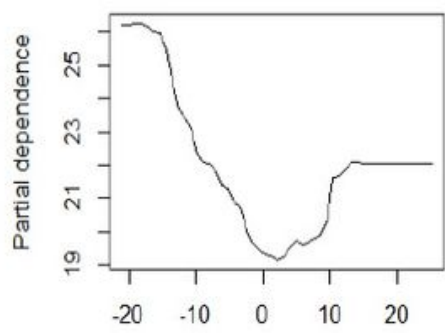

TPI_Lower

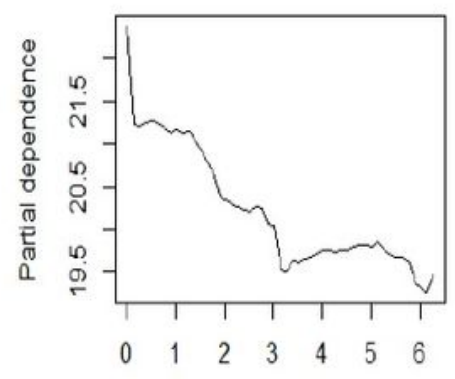

Aspect_Lower

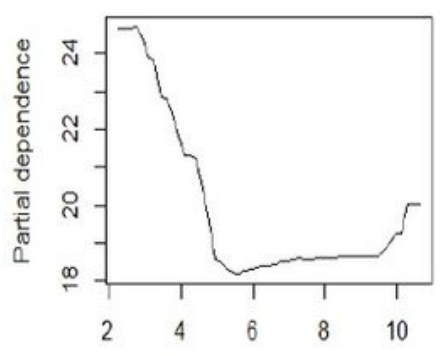

SW_Lower
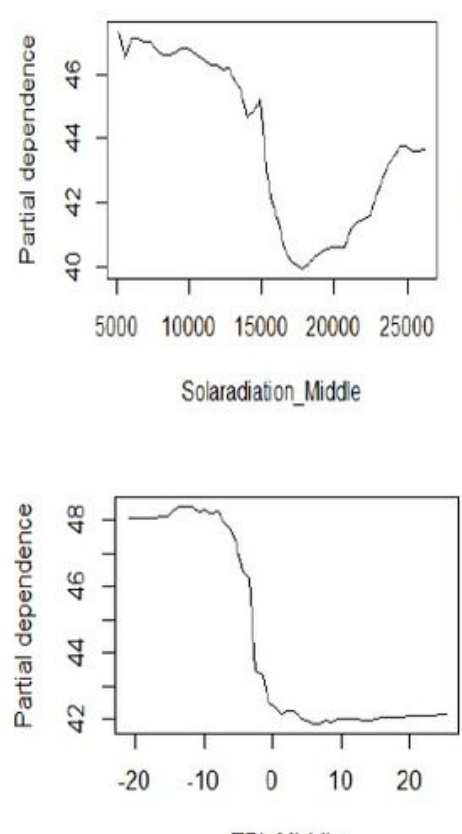

TPI_Middle
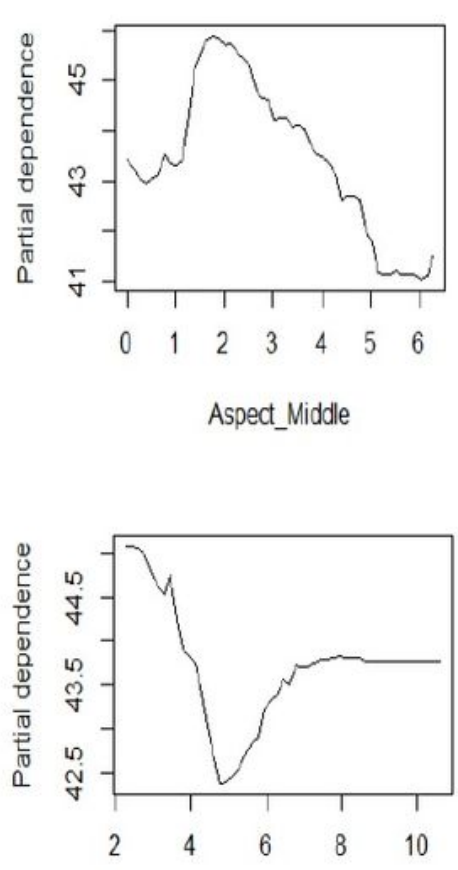

SWI_Middle
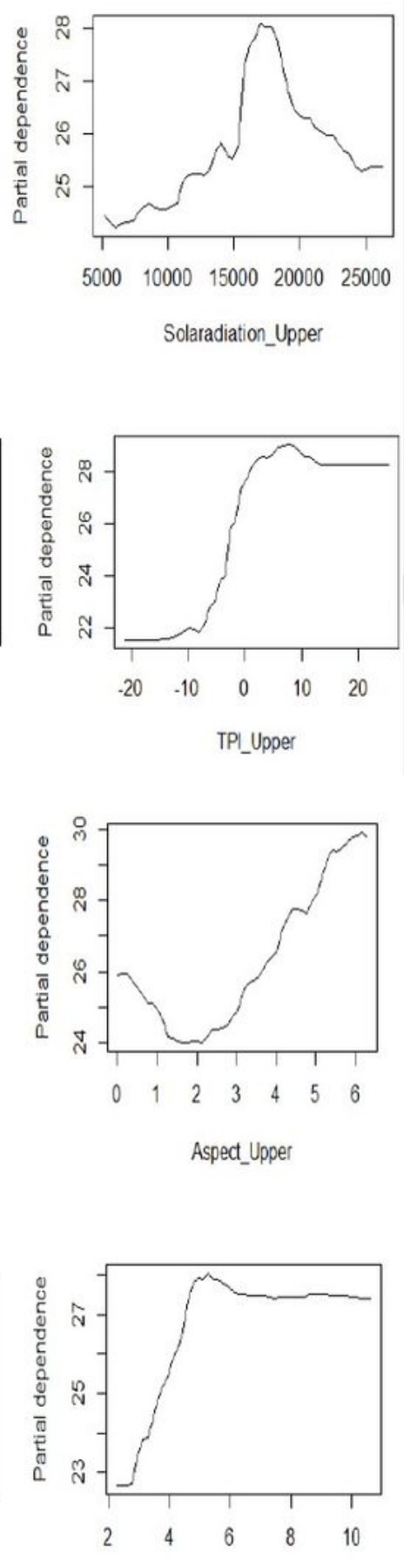

SW_Upper

\section{Figure 6}

Partial dependence plots of solar radiation, terrain position index (TPI), aspect, and SAGA wetness index (SWI) for random forest models of the three forest layers. Higher partial dependence values indicate a greater influence of the variables on the model. 

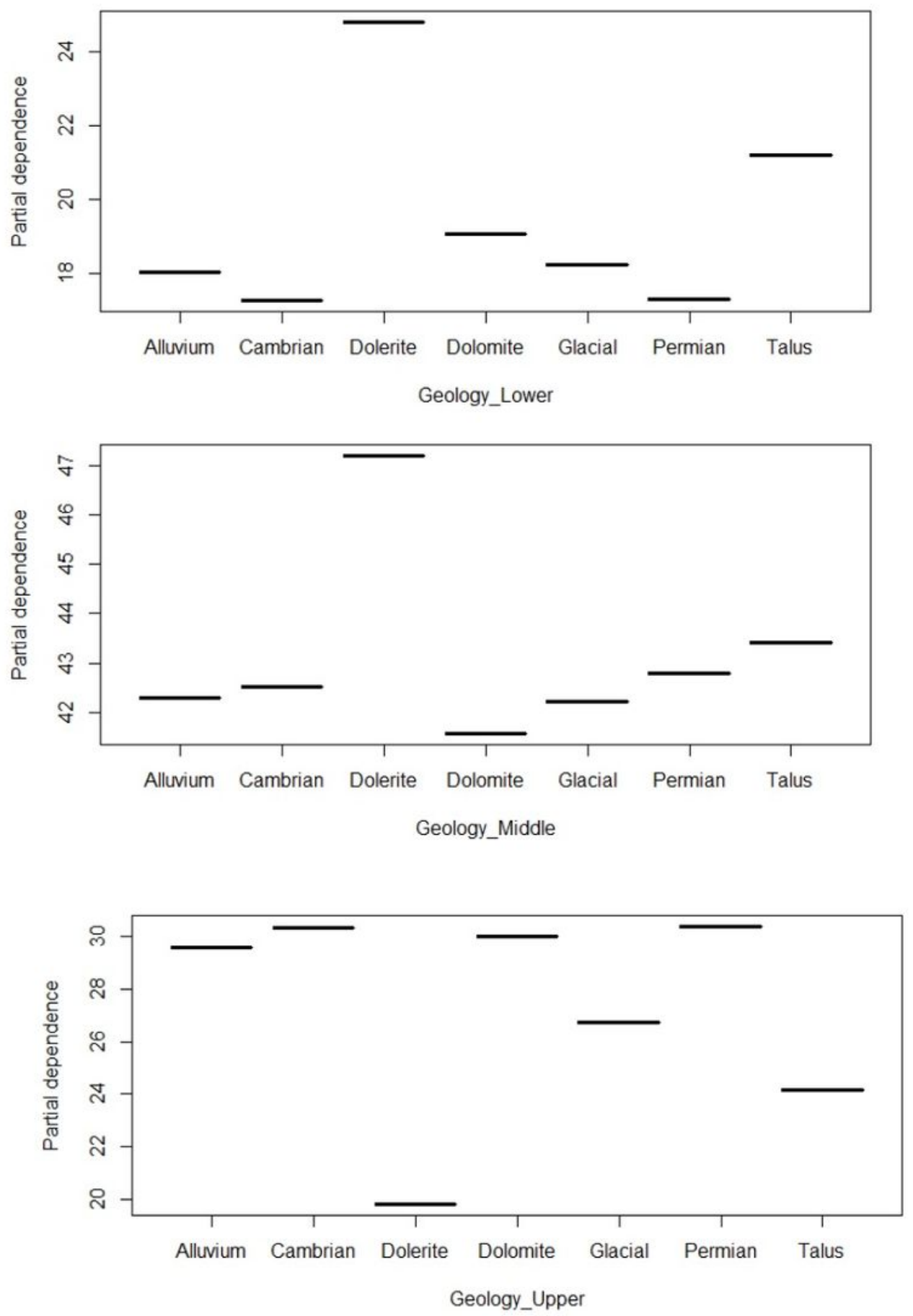

\section{Figure 7}

Partial dependence plots of geology. The acronyms used are Quaternary alluvium (Alluvium), Cambrian siliceous sediments (Cambrian), Jurassic dolerite (Dolerite), Neoproterozoic dolomite (Dolomite), Glacial tills (Glacial), Permian sediments (Permian), and Dolerite talus (Talus). All Permian sedimentary rocks were integrated into a single category; the carbonaceous rock types Ordovician limestones and Cambrian 
dolomite were combined; Dolerite boulders were merged with Dolerite talus; Quaternary sediments were merged with Quaternary alluvium. 